\title{
RECOMENDACIONES PARA LA ATENCIÓN DE RECIEN NACIDOS HIJOS DE MADRE COVID-19 POSITIVAS
}

\section{RECOMMENDATIONS FOR THE CARE OF NEWBORN CHILDREN OF COVID-19 POSITIVE MOTHERS}

\author{
Carmen Rosa Dávila Aliaga ${ }^{1, a}$, Elsa Torres Marcos ${ }^{1, b}$, J.Rosmary Hinojosa Perez $^{1, c}$, Ylia Espinoza Vivas ${ }^{1, d}$
}

\section{INTRODUCCIÓN}

La COVID-19 fue declarada pandemia mundial por la OMS el 11 de marzo del 2020, en la actualidad hay más de 34 millones de personas infectadas en el mundo y más de un millón han fallecido ${ }^{1,2}$. Dong reportó de un total de 2,135 niños afectados solo el $1.5 \%$ en edad neonatal ${ }^{3}$.

En el Perú, al 30 de setiembre del 2020, se han reportado 818,290 infectados y 32,535 fallecidos. Según el registro de NOTI-CDC-MINSA Perú hasta el 20 de setiembre del presente año, 6183 recién nacidos sospechosos a COVID-19, representa una incidencia acumulada de $17.93 \times 1000$ nacimientos. Por otro lado, notificaron 313 casos positivos con PCRrt, de ellos fallecieron 24 recién nacidos ${ }^{4}$.

Los niños de todas las edades pueden enfermar con COVID-19, la mayoría no se enferman con tanta gravedad como los adultos, y algunos quizás no presenten síntomas. Los índices de hospitalización para niños han sido mucho más bajos que para los adultos ${ }^{5-8}$.

En estos momentos existen pocos datos epidemiológicos de la enfermedad en neonatos y menos aún de seguimiento de estos casos. La Red de la Sociedad Iberoamericana de Neonatología reportó que de 86 mujeres embarazadas con COVID-19, 6\% de los recién nacidos fueron prematuros, 7\% dieron positivo al PCRrt, ninguno falleció, 76\% separó al binomio, en $95 \%$ de los casos la madre no pudo ser acompañada en el parto ni puerperio, solo $24 \%$ de las madres fueron autorizadas a amamantar ${ }^{9}$. Esta es una realidad que grafica parte de las consecuencias de la pandemia en la atención neonatal ${ }^{10}$.

Luego de 6 meses de pandemia podemos analizar la experiencia desarrollada en el mundo y particularmente en el Instituto Nacional Materno Perinatal, donde en el período Abril-Agosto 2020, atendimos a 1346 recién nacidos, hijos de madres infectadas por SARS COV 2, el $2.8 \%$ de esta población presentó PCR-rt positiva. Durante este tiempo tuvimos que trabajar, en el aspecto normativo, recursos humanos, infraestructura, equipamiento, dotación de materiales, medicamentos, adecuación de procesos y flujos, etc.; permitiéndonos alcanzar recomendaciones, para que los servicios de salud encargados de la atención de los hijos de las madres confirmadas o sospechosas de COVID 19, brinden una atención oportuna, segura y de calidad a los recién nacidos y sus familia.

\section{MECANISMO DE TRANSMISIÓN}

Se considera transmisión vertical intraútero, intraparto y periparto de difícil demostración. Son escasos los estudios que han demostrado la presencia del virus en fluidos genitales, líquido amniótico, placenta y sangre del bebé. Casi ausente los que identificaron partículas virales por PCR rt en la leche materna ${ }^{5-7}$.

Por otro lado, los recién nacidos pueden infectarse con SARS COV 2 por transmisión horizontal como el resto de la población, por exposición a cuidadores enfermos después del parto. La transmisión es de persona-persona, por areosoles

\footnotetext{
Instituto Nacional Materno Perinatal. Lima-Perú.

a Médico Pediatra Neonatóloga, Directora Ejecutiva de Neonatología en el INMP.

b Médico Pediatra Neonatóloga, Jefa del Servicio de Atención Inmediata y Emergencia en el INMP.

Médico Pediatra Neonatóloga, médico asistente del Departamento de Neonatología del INMP.

d Médico Pediatra Neonatóloga, Jefa del Servicio de Cuidados Intermedios neonatales en el INMP.

Citar como: Dávila CR, Torres E, Hinojosa JR, Espinoza Y. Recomendaciones para la atencion de recien nacidos hijos de madre COVID-19 positivas. Rev Peru Investig Matern Perinat 2020; 9(3):35-39

DOI https://doi.org/10.33421/inmp.2020211
}

Recibido: 13-09-20 Aprobado: 30-09-20 
emitidos después de un contacto cercano con una persona infectada, al toser, estornudar ó hablar.

La eliminación del virus en heces ha sido demostrada en algunos pacientes hasta por 5 meses ${ }^{11}$.

\section{PERIODO DE INCUBACIÓN}

Tiene un Rango de 1 a 14 días $^{5-7}$, con un promedio de Inicio de síntomas entre 5 a 6 días después de la infección.

\section{PERIODO DE TRANSMISIBILIDAD ${ }^{5-7}$}

Hasta siete (07), días después del inicio de síntomas (en promedio), pero puede extenderse hasta 14 días. Se estima que la transmisión podría iniciar antes de la presentación de síntomas.

\section{DEFINICIÓN DE CASO ${ }^{12}$}

\section{A. Caso Neonatal sospechoso}

RN hijo de madre con infección sospechosa o confirmada de COVID-19, o con historia de contacto estrecho con caso probable o confirmado, o recién nacido sintomático con prueba serológica lgM / lgM - IgG positiva.

B. Caso Neonatal confirmado

Recién nacido con prueba molecular para COVID-19 positiva.

C. Caso Neonatal descartado:

Recién nacido, asintomático y con prueba molecular para COVID-19 negativa.

\section{Caso madre sospechosa de covid-19}

Madre con sintomatología compatible con COVID 19 o antecedente de contacto con diagnóstico confirmado, y/o con serología (prueba rápida) positiva para lgM ó $\lg M-\lg G$.

\section{E. Caso Madre confirmada de COVID 19} Madre con prueba molecular positiva (PCR-tr).

\section{CUADRO CLÍNICO 5-7,12,13}

El cuadro clínico en el Recién nacido es inespecífico, puede ser similar a aquellas infecciones causadas por otros virus respiratorios. Se considerará sospechoso si presenta:

- Cuadro respiratorio, (tos, dificultad respiratoria)

- Distensión abdominal, vómito, diarrea

- Fiebre, alteraciones cutáneas.

\section{DIAGNOSTICO POR LABORATORIO7,12,14,15}

- El diagnóstico se hará con la prueba molecular con Reacción de Cadena polimerasa en tiempo real (PCR- tr) específica

- En el recién nacido sintomático que ingresa por emergencia o que procede de los servicios de hospitalización no COVID se realizará mediante la combinación de la prueba rápida para COVID 19 y la prueba molecular de PCR-tr

\section{MANEJO DEL RECIEN NACIDO}

1. MANEJO DEL RECIEN NACIDO EN SALA DE PARTOS Y SALA DE OPERACIONES HIJO DE MADRE SOSPECHOSA O CONFIRMADA DE COVID-19

\section{Anticipación:}

- Identificar factores de riesgo perinatal.

- Preparar recursos, equipos e insumos para la recepción del recién nacido:

\section{Durante el nacimiento:}

Se supervisará en la madre el uso adecuado de la mascarilla quirúrgica, manos y ropa limpias. RN vigoroso, se realizará la atención inmediata de rutina

- Realizar contacto piel a piel durante 60 minutos ininterrumpidos, Se aplica si la madre y el recién nacido se encuentran en buen estado.

- Ligar el cordón umbilical entre 2 a 3 minutos después del nacimiento.

- Se dará inicio a la lactancia materna dentro de la primera hora de vida.

Si el RN requiere reanimación, es prematuro o evidencia otras morbilidades, se debe realizar corte inmediato del cordón umbilical, trasladar a la servocuna e iniciar los procedimientos necesarios hasta su estabilización (RCP, administración de surfactante entre otros).

Se recomienda el uso de filtro viral / bacteriano (EPA 10 o hidroscópico), el cual se debe colocar entre la mascarilla o tubo endotraqueal y la bolsa autoinflable o pieza en $\mathrm{T}$.

\section{MANEJO DEL RECIEN NACIDO ASINTOMATICO,} HIJO DE MADRE CONFIRMADA DE COVID-19

- El recién nacido asintomático pasará con la madre a las salas de aislamiento para casos COVID-19 y realizará alojamiento conjunto supervisado.

- Si la madre es asintomática u oligosintomática con prueba rápida IgM o IgM-IgG positiva: $\mathrm{El}$ $\mathrm{RN}$ debe recibir lactancia materna exclusiva para lo cual la madre deberá usar mascarilla y lavado de manos estricto antes y después de la lactancia. Cuando no está lactando debe permanecer en una cuna al pie de la cama materna a 1.5 a 2 metros 
de distancia de esta. No deberá compartir la cama materna.

- Si la madre es sintomática severa con prueba rápida IgM, o IgM-IgG positiva: El recién nacido debe ser alimentado con leche materna extraída.

- La prueba molecular (PCR- tr ), hisopado naso faríngeo, se realizará a todos los $\mathrm{RN}$ antes de las 24 horas de vida y los resultados se informaran en el seguimiento telefónico

- El recién nacido debe ser dado de alta, junto con la madre.

\section{MANEJO DEL RECIEN NACIDO SINTOMATICO Y/O PREMATURO, HIJO DE MADRE SOSPECHOSA O CONFIRMADA DE COVID-19}

- El RN que presenta morbilidad o prematuridad al nacer (parto vía vaginal o cesárea), será hospitalizado en servicios diferenciados (COVID 19) de UCIN e Intermedios; será considerado sospechoso y se mantendrá en aislamiento, hasta contar con el resultado de la PCR tr que será tomada antes de las 24 horas de nacido.

- El manejo terapéutico será el correspondiente según guía de práctica clínica de la morbilidad presente.

- Completar estudios de laboratorios e imágenes para detectar compromiso multiorgánico (Perfil hepático, renal, de coagulación, Rx torax)

- Si la prueba molecular es negativa se descartará la COVID-19, y continuará su manejo terapéutico en las salas no COVID-19 hasta el alta.

- Si la prueba molecular es positiva el recién nacido, será considerado como Caso confirmado COVID-19, continuará su manejo terapéutico, según la patología de fondo, en la sala de aislamiento hasta completar 14 días de aislamiento. Se realizará la prueba molecular de control, al ser negativa se procederá al alta o pasará a hospitalización para RN no COVID según su patología hasta completar su tratamiento.

4. MANEJO DEL RECIEN NACIDO SINTOMATICO, SOSPECHOSO DE COVID-19 QUE INGRESA POR EMERGENCIA O PROCEDE DE HOSPITALIZACIÓN NO COVID

- El RN sintomático que ingresa al Servicio de Emergencia deberá ser tamizado con la prueba rápida para decidir la atención diferenciada; si requiere hospitalización y la prueba rápida es IgM, o lgM-lgG positiva para COVID-19 será hospitalizado según su morbilidad en las áreas de UCIN o Intermedios diferenciadas para COVID 19. Y el manejo terapéutico será de acuerdo a las guías clínicas de atención de la patología que motiva su ingreso.

- Se realizará el hisopado nasofaríngeo para la PCR-tr, exámenes de laboratorio e imágenes en busca de confirmación diagnóstica.

- El uso de antibióticos está limitado a los casos en que se sospeche o compruebe infección bacteriana agregada.

- Si la prueba de PCR-tr es positiva se mantendrá en aislamiento hasta el alta o hasta que la PCR-tr de control sea negativa.

\section{PROCEDIMIENTOS DE BIOSEGURIDAD PARA LA ATENCION DEL RECIEN NACIDO SOSPECHOSO O CONFIRMADO DE COVID 19:}

- El Equipo de salud, usará los elementos de protección personal (EPP), de acuerdo a los criterios para cada sala de aislamiento, será instruido y supervisado en el correcto uso de los EPP tanto al ingreso como a la salida de las salas de aislamiento.

- Se recomienda un equipo de personal separado para la atención de casos sospechosos o confirmados con COVID-19

- El personal de seguridad, limpieza y administración, deberá contar con EPP correspondiente, asimismo, recibir información y formación sobre la prevención de la infección.

- Las visitas se restringirán a una sola persona asintomática, y sin contacto con personas enfermas de COVID 19; se establecerá periodicidad tiempo de permanencia. Deberá ser instruida para que mantenga las medidas de distanciamiento social y el uso correcto de mascarilla y lavado de manos a su ingreso.

\section{TRANSPORTE NEONATAL}

El transporte neonatal intrahospitalario como extrahospitalario, se realizará en incubadora de transporte exclusivo para pacientes COVID-19.

El personal que transporta usará EPP correspondiente. Al término del transporte la incubadora deberá ser desinfectada según protocolo de desinfección establecido en la institución.

\section{ALTA Y EL SEGUIMIENTO DE LOS RECIEN NACIDOS DE MADRE COVID 19 \\ Criterios de alta:}

a. Caso RN confirmado asintomático: Se da el alta junto con la madre

b. Caso RN confirmado sintomático: Se da el alta cuando el cuadro clínico esté superado y/ o la prueba molecular de control sea negativa.

Indicaciones al alta:

a. El recién nacido asintomático sale de alta con la madre. Si la madre requiere hospitalización el alta será dada con familiar. 
b. La madre permanecerá en aislamiento en casa hasta terminar la cuarentena.

c. La madre debe continuar en casa con medidas de protección estrictas: Distanciamiento, lavado de manos, uso de mascarilla permanente mientras dure la cuarentena.

d. El recién nacido debe recibir lactancia materna con la protección descrita para madre y el lavado de manos antes y después de atenderlo.

e. Después de amamantarlo el RN quedará en una cuna al pie de la cama a 1.5 a 2 metros de distancia de ella, hasta cumplir con la cuarentena.

f. La madre debe recibir información, sobre detección de signos de alarma en el RN.-

g. En el hogar deberán evitar los contactos sociales y familiares y no asistir a áreas públicas innecesariamente.

h. Ventilación y aseo de las habitaciones de manera periódica.

\section{Seguimiento del recién nacido}

a. Se realizará el seguimiento telefónico y/o presencial de los RN egresados de UCIN e intermedios COVID 19.

b. Los neonatos con diagnóstico confirmado de COVID 19, se incluirán en el Programa de Seguimiento para Niños de Alto Riesgo (NAR) según protocolo del servicio.

c. Los niños de alojamiento conjunto en las salas de aislamiento serán seguidos en los establecimientos de la Red de salud que correspondan.

\section{LACTANCIA MATERNA EN EL CONTEXTO COVID-19}

Enfatizamos la importancia de la Lactancia Materna para todos los recién nacidos, sin distinción ${ }^{16}$. La leche materna protege de agentes infecciosos bacterianos y virales, hay reportes de anticuerpos específicos contra coronavirus en la leche humana. ${ }^{17,18}$

La evidencia científica actual en relación a este tema señala que, el contacto prolongado piel con piel y la lactancia materna temprana y exclusiva siguen siendo las mejores estrategias para reducir los riesgos de morbilidad y mortalidad tanto para la madre con COVID- 19 como para su bebé ${ }^{18,19}$

Por otro lado las organizaciones internacionales como OMS, UNICEF, OPS, consensos europeos y americanos, así como guías de atención recomiendan continuar con la lactancia materna en los RN hijos de madres sospechosas o confirmadas con COVID-1916,20,21.

Por tanto rrecomendamos, rescatar las prácticas beneficiosas en la atención del parto y del recién nacido para mantener juntos a la madre y recién nacido, con el cumplimiento de las medidas de bioseguridad requeridas.

\section{INMUNIZACIONES EN EL CONTEXTO COVID-19}

Se debe garantizar la inmunización a los recién nacidos dentro de las primeras 12 horas de vida según el esquema nacional de vacunación tanto para tuberculosis (BCG), como hepatitis B (HVB).

Si la madre es COVID-19 positiva y HvB positiva se procederá a la inmunización para HvB y la administración de inmunoglobulina específica para HvB en las primeras 12 horas de vida según el protocolo estándar del manejo del hijo de madre portadora de HvB.

\section{REFERENCIAS BIBLIOGRÁFICAS}

1. Pan American health organization. Dayly report COVID 19on America. Last Updated: October 10 2020. https://pahocovid19-response-who.hub.arcgis.com/

2. Dong $\mathrm{Y}, \mathrm{Mo} \mathrm{X}, \mathrm{Hu} \mathrm{Y}$, et al. Epidemiological characteristics of 2143 pediatric patients with 2019 coronavirus disease in China. Pediatrics. 2020; doi: 10.1542/peds.2020-0702.

3. World Health Organization. Report of the WHO-China Joint Mission on Coronavirus Disease 2019 (COVID-19). Geneve: World Health Organization; 2020 Disponible en: https://www. who.int/docs/default-source/coronaviruse/who-china-jointmission-on-covid-19-final-report.pdf

4. Alertas epidemiológicas del Centro Nacional de Epidemiología, Prevención y Control de Enfermedades, bajo el acápite de Vigilancia, Prevención y Control del COVID-19. Disponible en: https://www.dge.gob.pe/portal/index.php?option=com content\&view $=$ article\&id $=678$

5. Qi Lu, Yuan Chi. Coronavirus disease (COVID $\square$ 19) and neonate: What neonatologist need to know- available 01 March 2020 en https://onlinelibrary.wiley.com/doi/full/10.1002/ jmv. 25740

6. Scwartz DAAn analisis of 38 pregnant women with COVID-19, their newborn infants, and maternal-fetal transmission of SARS-CoV.2: Maternal coronavirus infections and pregnancy outcomes. Arch Pathol Lab Med 2020 March 17

7. Center for disease control and prevention. Coronavirus disease 2019. Evaluation and Management Considerations for Neonates At Risk for COVID-19. Update 10 october 2020. https://www.cdc.gov/coronavirus/2019-ncov/hcp/caring-fornewborns.htm

8. DOCUMENTO TÉCNICO: Atención y Manejo Clínico de Casos de COVID-19. Escenario de Transmisión Focalizada. Aprobado mediante Resolución Ministerial № 084-2020/ MINSA. Disponible en: https://cdn.www.gob.pe/uploads/ document/file/565556/Documento_T\%C3\%A9cnico Atenci\%C3\%B3n_y_Manejo_Cl\%C3\%ADnico_de_Casos_ de_COVID-19.pdf

9. Sola A, Rodríguez S, Cardetti M, Dávila C. COVID-19 perinatal en América Latina. Rev Panam Salud Publica. 2020;44e:47. https://doi.org/10.26633/RPSP.2020.47

10. Arnaez J, Montes MT, Herranz-Rubia N and Garcia-Alix A (2020) The Impact of the Current SARS-CoV-2 Pandemic on Neonatal Care. Front. Pediatr. 8:247. doi: 10.3389/ fped.2020.00247

11. Tang A, Tong Z, Wang H, Dai X, Liu J, et al. Detection of novel coronavirus by RT-PCR in stool specimen from asymptomatic 
child, China. Emerg Infect Dis (6) (2020 Jun 17), p. 26

12. DS 97-MINSA-2020/DGIESP. Directiva sanitaria para la prevención y atención de la gestante y del recién nacido con riesgo a COVID 19. Aprobado con RM 245-2020-MINSA. 30 de Junio 2020.

13. Documento técnico Manejo de la mujer embarazada y el recién nacido con COVID-19 Versión de 13 de mayo de 2020 Disponible en https://www.mscbs.gob.es/profesionales/ saludPublica/ccayes/alertasActual/nCov-China/documentos/ Documento_manejo_embarazo_recien_nacido.pdf

14. Subsecretaría de Salud Pública- Subsecretaría de Redes Asistenciales División de Prevención y Control de Enfermedades, Departamento de Ciclo Vital; División de Gestión de la Red Asistencial, Departamento de Procesos Clínicos y Gestión Hospitalaria; Dpto. Gestión Táctica de Redes Ministerio de Salud Gobierno de Chile. Protocolo Medidas de Prevención de Infección por Covid-19 En Unidades De Neonatología. Marzo 2020.

15. Guía de atención del recién nacido sospechoso o confirmado de infección por coronavirus (SARS COV-2) del Instituto Nacional Materno Perinatal, aprobado con RD Nª90-2020DG-INMP/MINSA. Junio 2020.

16. Interim Guidance on Breastfeeding for a Mother Confirmed or Under Investigation For COVID-19. CDC. Disponible en: https://www.cdc.gov/coronavirus/2019-ncov/specific-groups/ pregnancy-guidance-breastfeeding.html.
17. Fernandez-Carrasco F y col. Coronavirus Covid-19 Infection and breastfeeding: and exploratory review. Rev Esp Salud Pública. Mayo 2020

18. Lubbe W, et al. Breastfeeding during the COVID-19 pandemic -a literature review for clinical practice Int Breastfeed J.2020 Sep $14 ; 15(1): 82$

19. Davanzo $\mathrm{R}$, et al. Breastfeeding and Coronavirus disease-2019 :Ad interim indications of the Italian Society of Neonatology endorsed by the Union of European Neonatal \&Perinatal Societes. Matern CHild Nutr. 2020 Jul; 16(3)

20. Hoang Thi, et al. Appropriate care for neonates born to mothers with COVID-19 disease .Acta Paediatr. Sept 2020; 109(9):1713-1716

21. Walker K, et al. Maternal transmission of SARS-VOV-2 to the neonate and possible routes for such transmission: a systematic review and critical analysis. BJOG. 2020 Oct; 127(11):1324-1336

\section{Correspodencia:}

Carmen Rosa Dávila Aliaga

Dirección: Instituto Nacional Materno Perinatal. Jr. Santa Rosa, 941. Cercado de Lima, Lima, Perú.

Correo: davilacarmen@hotmail.com

Teléfono: 999042084 